\title{
Multiple HPA Profiles in Endogenous Depression: Effect of Age and Sex on Cortisol and Beta-Endorphin
}

\author{
H. Akil, R. F. Haskett, E. A. Young, L. Grunhaus, J. Kotun, \\ V. Weinberg, J. Greden, and S. J. Watson
}

\begin{abstract}
We have previously shown that a number of depressed patients demonstrated a failure to suppress corticotrophic secretion, as measured by $\beta$-Endorphin/ $\beta$-Lipotropin ( $\beta$-End/ $/ \mathrm{E}-\mathrm{L} P H$ levels), following dexamethasone challenge. The current study is an extension and replication of these findings, as well as an analysis of some of the biological variables which may contribute to the variance in $\beta$-End/ $\beta$-LPH nonsuppression. We continue to observe a high rate of $\beta$ End/ $\beta$ LPH nonsuppression in depressed patients following dexamethasone; this escape at the pituitary level is even observed in a number of patients who demonstrate normal cortisol suppression. Advancing age, particularly in women, led to higher baseline cortisol, lower baseline $\beta-E n d / \beta-L P H$, and a greater likelihood of being a nonsuppressor on one or both measures.
\end{abstract}

\section{Introduction}

It is well established that a proportion of patients with endogenous depression hypersecrete cortisol and show elevated plasma cortisol during both active and inactive cortisol secretory phases (Sachar 1967; Sachar et al 1970, 1973; Carroll et al 1967a; Pfohl et al 1985; Rubin et al 1967; Halbreich 1985). In addition to cortisol hypersecretion, as many as two-thirds of endogenously depressed patients also fail to suppress cortisol or show an early escape from the suppressive effects of $1 \mathrm{mg}$ of dexamethasone. Although both of these cortisol abnormalities are present in endogenously depressed patients, they do not necessarily occur in the same individual (Carroll et al 1976b, 1981). The work of Carroli and collaborators (1981) initially suggested that this failure to suppress cortisol fol-

From the Department of Psychiatry. University of Michigan. Ann Arbor. MI. Address reprint requests to Dr. H. Akil, Department of Psychiatry, University of Michigan, 205 Washtanan Place. Ann Arbor, MI 48109-0720.

Received May 9. 1991; revised May 29, 1992. lowing dexamethasone challenge was specific to endogenous depression/melancholia. Many patients who meet Research Diagnostic Criteria (RDC) criteria for major depressive disorder-but who do not meet the criteria for endogenous subtype, show normal suppression of cortisol with dexamethasone (Carroll et al 1981, 1980; Bloan and Inuey 1980; Schlesser et al 1979). Limbic system dysfunction is the hypothesized defect underlying both cortisol hypersecretion and dexamethasone nonsuppression. The presumed mechanism is increased release of corticotropin releasing hormone ( $\mathrm{CRH}$ ) from the hypothalamus resulting in increased release of adrenocorticotropic hormone (ACTH) from the anterior pituitary and subsequent increased cortisol secretion from the adrenal (Carroll et al 1967a; Gold et al 1986). Although such a theory may explain the cortisol data, it should be remembered that there are a number of different leveis of the hypothalamic pituitary adrenal axis (HPA) intervening between the brain and adrenal, and that each level may have regulatory mechanisms that modify the signal transmission rather than transmit the signal 
unchanged. In addition, the failure to suppress cortisol after dexamethasone involves feedback mechanisms at multiple levels of the HPA axis. Thus, it may reflect several abnormalities such as decreased sensitivity to the inhibitory effects of dexamethasone, a change in set point for steroid inhibition, or even adrenal hypertrophy rather than an increased drive to secrete via increased CRH release. Indeed, studies using CRH have suggested abnormalities downstream from CRH secretion, either due to altered pituitary sensitivity or altered circulating levels of steroids (Gold et al 1986; Holsboer et al 1984; Young et al 1990). Thus, in attempting to understand the abnormal response to dexamethasone it is critical to explore multiple levels of the HPA axis examining both resting levels and responsiveness to the challenge.

Studies focusing on pituitary regulation in depressed subjects have identified complex regulatory mechanisms. Many of these studies have measured either ACTH levels or $\beta$-endorphin/ $\beta$-lipotropin levels ( $\beta$-END/ $\beta$-LPH). ACTH and $\beta$-endorphin are synthesized from a common precursor that is packaged into the secretory granules of the anterior lobe corticotrophs prior to being processed. Thus, each granule contains equimolar amounts of the ACTH domain and the $\beta-E N D / \beta-L P H$ domain. These two domains are then released equimolarly on secretory signals (Eipper and Mains 1990; Young and Al:il 1985; Guillemin et al 1977). Thus, either ACTH measures, or $\beta$-END/ $\beta$-LPH measures in plasma, when properly characterized, can be used as indices for the activity of the anterior lobe corticotroph. Several investigators (Pfohl et al 1985; Kalin et al 1982; Risch 1982; Nasr et al 1983) have reported that major depressive disorder (MDD) subjects who are Dexamethasone Suppression Test (DST) nonsuppressors have shown elevated resting levels of either ACTH or $\beta$-endorphin. Other investigators have failed to find such differences in resting ACTH or $\beta$-endorphin levels between DST suppressors or nonsuppressors, or among DST suppressors, nonsuppressors, and normal controls (Fang et al 1981; Reus et al 1982; Matthews et al 1986). Some of the variability in these studies may be contributed by differences in diagnostic subgroups, because most studies included all patients with MDD, regardless of whether they met criteria for endogenous subtype. When examining plasma ACTH or $\beta$-END levels after dexamethasone challenge, the reports still show some disagreement; however, most groups agree that cortisol nonsuppressors demonstrate higher ACTH levels following dexamethasone as compared to cortisol suppressors (Pfohl et al 1985; Kalin et al 1982; Nasr et al 1983; Reus et al 1982, 1983; Yerevanian et al 1983; Holsboer et al 1983; Berger et al 1985). Only a few investigators report no difference in postdexamethasone ACTH among DST suppressors, DST nonsuppressors, and normal controls. (Fang et al 1981; Yerevanian and Woolf 1983).
The failure to demonstrate differences in ACTH values following dexamethasone challenge between any depressed subgroups and normal controls has led Fang et al. (1981) to suggest a possible adrenal dysfunction in depression, a suggestion that was lent some support by the report of Amsterdam et al (1985) showing an increased cortisol response to ACTH 1-24 infusion in MDD patients compared to normal subjects. What emerges from these studies is that more MDD patients appear to show abnormalities with feedback challenge (dexamethasone) than with measurements of resting levels, and, that there may be dysregulation of the HPA axis at more than one level resulting from biological heterogeneity in the adaptation mechanisms used across levels of the HPA axis.

A major difficulty faced in the studies of pituitary regulation in affective disease involves the definition of what constitutes a normal or abnormal peptide response to dexamethasone challenge. If postdexamethasone peptide levels are averaged together for all subjects of a particular diagnostic group, it may lead to failure to observe a significant postdexamethasone difference between MDD patients and psychiatric controls. This is caused by the biological heterogeneity within the MDD population as well as to substantial interindividual variation of resting ACTH and $\beta$ endorphin levels. For cortisol, when a cut-off criterion is employed to define suppression for an individual subject, such as in the standardized dexamethasone suppression test, $30 \%-60 \%$ of the MDD endogenously depressed subjects emerge as nonsuppressors (Carroll et al 1981; Schlasser et al 1989; Matthews et al 1986; Amsterdam et al 1982; Stokes et al 1984; Copper et al 1983). Unfortunately, equivalent cut-off criteria are not easily established for either plasma

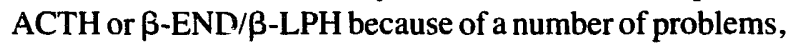
most prominently the variance in the peptide assays. To counter this problem, rather than looking at mean postdexamethasone $\beta$-endorphin levels across diagnostic groups, we have proposed two criteria to determine lack of suppression of plasma peptide levels. The first criterion uses the same concept of referent values that was employed for determining the cortisol cut-off criterion. It simply consisted of a postdexamethasone $\beta$-endorphin value larger than 2 fmoles $/ \mathrm{ml}$. This referent cut-off value was used because over 90\% of our controls had postdexamethasone $\beta$-endorphin levels below that level. We also proposed an aiternative strategy that used each subject as his or her own control (Matthews et al 1986). It involved the following method: four basal samples and four matched postdexamethasone samples are obtained for a given subject, and the mean and standard errors of the mean (SEM) for each set of samples is computed. In control subjects, dexamethasone suppresses plasma $\beta$-END/ $\beta$-LPH levels such that there is no overiap of the means \pm SEM between the postdex and the predex samples. If this "overlap" criterion is used in MDD 
patients, a number of them "fail to suppress", that is, exhibit overlapping standard errors of the predex and postdex means (Matthews et al 1986). This alternative approach uses an individual criterion of suppression and does not require an absolute cut-off. Neither of these criteria has been fully validated to date, nor is it clear that either one will represent the ultimate yardstick by which to define dexamethasone nonsuppression or "dex-abnormality" at the level of the pituitary corticotrophs. Their theoretical advantages have been discussed previously (Matthews et al 1986). However, we need to determine empirically whether they continue to yield meaningful data vis-à-vis the HPA dysregulation in depression. In general, we have favored the use of the "overlap" criterion because it depends exclusively on within subject comparisons, all carried out in one assay, and avoids interassay variability, which can be problematic in peptide measurements. Finally, it should be noted that a third measure was also used by our group (Meador-Woodruff et al 1987) in examining the relationship between dexamethasone effect on $\beta$-endorphin and severity of depression. This measure essentially depended on the ratio of postdex levels to predex $\beta$-endorphin levels, for each individual patient. However, in a series of comparison's across inore ihan 100 subjects, it has become apparent that the overlap and the ratio method lead to essentially identical conclusions (i.e., most subjects who have suppressed by $40 \%$ will have suppressed by the overlap criterion and vice versa). The feature that all three criteria share is that they attempt to gauge the corticotrophic response for each individual subject, rather than looking at group means.

Using the overlap criterion, we have reported two major observations (1) over $50 \%$ of the MDD patients exhibit a $\beta$-END/ $\beta$-LPH escape from dex at $4 \mathrm{PM}$, as compared to $8 \%-11 \%$ in psychiatric controls, and (2) there is only partial concordance between an abnormal $\beta-E N D / \beta-\mathrm{LPH}$ response and an abnormal cortisol response to dexamethasone. As a result, combining the two HPA tests led to a high rate of abnormality in the MDD patients (69\%-72\%) as compared to non-MDD psychiatric controls (8\%-11\%) (Matthews et al 1986).

The purpose of the present study is three-fold: (1) to test the overlap criterion in a group of normal subjects, (2) to replicate in a separate patient group our previous report on the abnormal plasma $\beta-E N D / \beta-L P H$ response to dexamethasone challenge in MDD subjects, and (3) to further investigate the possible sources of variance or heterogeneity innuencing HPA axis functioning of MDD patients. Specifically, can we discriminate those patients likely to respond abnormally on the cortisol assay, the $\beta-E N D / \beta$ LPH assay, or both? In this study, we focused on factors such as the age and sex of the patients, as potentially important variables that determine patterns of abnormality in the HPA axis.

\section{Subjects and Methods}

\section{Normal Controls}

Sixteen consenting nonsmoking, nonjogging, control subjects ( 7 men, 9 women), 20-68 years old, were recruited by advertisement for participation in this study. Subjects were required to be medication and alcohol free for at least 2 weeks prior to the study, verified by a urine drug screen. All subjects received a physical exam and laboratory blood work for evaluation of electrolytes, liver functions, hematocratic/hemoglobin, and thyroid functions. All normal control subjects were screened for psychiatric illness by a structured interview, the SADS-L (Schedule for Affective Disorders and Schizophrenia-Lifetime). The studies were conducted on the Clinical Research Center at the University of Michigan Hospital.

\section{Fatients}

The 34 patients for this new study were patients on the Clinical Studies Unit in the Depression Program of the Department of Psychiatry, University of Michigan Medical Center over a period of 4 years. These data have not been included in any previol:sly published report.

All patients gave informed consent. After withdrawal from all medication, each completed a standard diagnostic evaluation. The assessment included two independent clinical interv.aws by a faculty psychiatrist and a psychiatry resident or a research fellow; a structured interview using the Schedule for Affective Disorders and Schizophrenia (SADS), conspleted bv a separate clinician; family interviews conducted by a social worker, seeking supplemental information about the clinical features and longitudinal course of the patient's disorder and family history cf psychiatric disorder; review of all previous medical records; and physical examination with clinical laboratory testing to identify any serious physical disorders. After completion of the evaluation, relevant clinical and research personnel assigned a consensual diagnosis to each patient using the RDC.

Patients were excluded from the study if they were unable to remain medication free for 14 days, or if at the time of presentation, they were taking medication known to interfere with interpretation of the dexamethasone test (Carroll 1985), were suffering from any serious physical illness, weighed less than $80 \%$ of ideal body weight, or were pregnant. Twenty-one patients met criteria for MDD, definite or probable endogenous subtype. Among the remaining 13,5, subjects had a diagnosis of mania and were analyzed separately; 8 subjects did not meet criteria for affective disorders and were termed psychiatric controls ( 2 schizophrenics, 4 schizoaffective, depressive type, 1 unspecified functional psychosis and 1 "other psychiatric disorder"). 


\section{Clinical Ratings}

At the time of the study protocol, the treating psychiatrist completed a clinical rating of uspressive symptoms using the 17-item Hamilton Depression Rating Scale (HDRS). All clinicians involved in the diagnostic procedure and completing clinical ratings are blind to the research laboratory data. Similarly, all laboratory assays are completed in the absence of any clinical information about the patient. As a further safeguard, all tubes are randomized and assayed without knowledge of the sample sequence during the experiment.

\section{Experimental Protocol}

All patients and controls were medication free for at least 14 days before completing the experimental protocol. On Day 1, at 1:30 PM, an intravenous catheter was inserted and the subject remained at rest until all samples were collected. At 3:30 PM, following $2 \mathrm{hr}$ of rest and adaptation, sampling began, and a total of 4 samples were taken at 20 min intervals (3:30 PM, 3:50 PM, 4:10 PM, and 4:30 PM). The subjects were given oral dexamethasone at 11 PM. Day 2 postdexamethasone sampling was identical to Day 1 sampling, with a catheter insertion at 1:30 PM and four samples drawn between 3:30 and 4:30 PM (Matthews et al 1986).

\section{Blood Collection}

Blood samples for the measurement of $\beta$-END/ $\beta$-LPH levels were collected in chilled EDTA-containing (Ethylene Diamine-Tetraacetate) vacutainers (BD Vacutainers Brand Becton-Dickinson). The samples immediately were chilled on ice and centrifuged at $4^{\circ} \mathrm{C}$ within $10 \mathrm{~min}$. The plasma was then acidified with $0.5 \mathrm{ml}$ in $\mathrm{HCl}$ and immediately stored at $-70^{\circ} \mathrm{C}$ until extraction.

\section{Biochemical Assays: $\beta-E N D / \beta-L P H, A C T H$, Cortisol}

1. Peptide Extraction for ACTH and $\beta$-END/ $\beta-L P H$ $R I A$. Plasma samples were extracted on Sep-Pak $\mathrm{C}_{18}$ cartridges prior to the radioimmunoassay (RIA) in order to concentrate the peptides within the limits of sensitivity of the assay and to remove nonspecific inhibitors of the RIA found in plasma. This extraction nrocedure is rapid, requiring only minutes, and it yields over $95 \%$ recovery for $\beta$-END, $\beta$-LPH, $\mathrm{ACTH}$, and proopiomelanocortin (POMC) (Cahill et al 1983). Following this procedure ACTH and $\beta$ END/ $\beta$-LFII are assayed using the RIA methods described below.

2. $\beta-E N D / \beta-L P H R I A$. The procedure for production of the antibody used in this assay has been detailed previously (Watson 1982). The serum harvested from the rabbit named Brenda was selected for use in measurement of $\beta$-END/ $\beta$-LPH-like immunoreactivity in human plasma because it was determined to be pariculáliy señsitive ât low final concentrations of antisera $(1: 20,000$ to $1: 100,000$ final dilution). At very high dilutions, the small population of antibodies exploited in the radioimmunoassay has high affinity for the antigen. The optimum final dilution is $1: 40,000$. The serum is not crossreactive with alpha-END ( $\beta$-END 1-16), gamma-END ( $\beta$ END 1-17), $\beta$-END 27-31 or des-tyrosine gammaEND ( $\beta$-END 1-17). The antigenic determinants of the Brenda antiserum at 1:40,000 final dilution are primarily between positions 17 to 27 of the $\beta$-END peptide, but there is also a modest carboxy-terminusrecognizing population. There is no crossreactivity at $1 \mu \mathrm{M}$ concentrations of [Met]Enk, [Leu]Enk, Dyn $\mathrm{A}$, Dyn $\mathrm{B}$, alpha-neoendorphin, $\mathrm{N}$-acetyl dynorphin, or a number of pituitary peptides of a nonopioid nature ( $\alpha M S H, A C T H, \gamma M S H)$. To maximize the sensitivity of the curve, disequilibrium incubation is used. In this procedure, the antibody and the unknown samples or standards are incubated in a total volume per assay tube of $0.150 \mathrm{ml}$ for $24 \mathrm{hr}$ at $4^{\circ} \mathrm{C}$. The tracer is then added to $0.100 \mathrm{ml}$ of RIA buffer $(150 \mathrm{mmol} / \mathrm{L}$ Na phosphate buffer with $1 \%$ $\mathrm{NaCl}$ and $0.3 \%$ human serum albumin $\mathrm{pH} 8.2$ ) bringing the total volume to $0.250 \mathrm{ml}$. The tubes are vortexed and again incubated at $4^{\circ} \mathrm{C}$ for overnight. The assay is separated by immunoprecipitation with sheep antirabbit immunoglobulin G (IgG). We can detect reliably 0.5-1 fmole of $\beta-E N D /$ $\beta$-LPH-like immunoreactivity per assay tube, with an $\mathrm{IC}_{50}$ of 12 fmoles. We typically add the equivalent of $2 \mathrm{ml}$ of extracted plasma/assay tube, allowing us to detect reliably values of $0.25-0.5 \mathrm{fmoles} / \mathrm{ml}$ of plasma. Each sample is run in triplicate, yielding less than $8 \%$ variability. Interassay variability within a given tracer is less than $10 \%$. However, with separate iodinations, intrassay variability can increase up to $17 \%$, and the system needs recalibration.

3. ACTH RIA. The antibody used for measuring ACTH in plasma was raised in rabbits, against synthetic ACTH coupled to thyroglobulin. Hence, this is a midportion antibody that recognizes full $\mathrm{ACTH}_{1-39}$ but has little or no crossreactivity with smaller peptides derived biosynthetically from ACTH, including $\alpha \mathrm{MSH}$ and corticotropin-like intermediate lobe peptide (CLIP, also known as $\mathrm{ACTH}_{18-39}$ ). Plasma samples were extracted on Sep-Pak $\mathrm{C}_{18}$ cartridges prior to determination of ACTH immunoreactivity, 
with nearly $100 \%$ extraction efficiency. The RIA was performed in a $0.15 \mathrm{mmol} / \mathrm{L}$ sodium phosphate buffer containing $0.10 \mathrm{mmol} / \mathrm{L} \mathrm{NaCl}, 0.004 \mathrm{mmol} / \mathrm{L}$ EDTA, $0.02 \%$ sodium azide, $0.1 \%$ polylysine at $\mathrm{pH}$ 7.6. The antiserum was used at a final dilution of $1: 80,000$ in the assay, and the radioligand was ${ }^{125} \mathrm{I}$ $\mathrm{ACTH}_{1-39}$. We can detect reliably 5 fmole of ACTH/assay tube with an $\mathrm{IC}_{50}$ of 50 fmoles. Intraassay variability is within $10 \%$.

4. Corticosteroid Assay. Plasma total corticosteroids ("cortisol") are measured by the competitive protein binding (CPB) technique of Pegg and Keane (1969) as modified by de la Pena and Goldzieher (1977). Plasma samples were extracted with ethanol rather than dichloromethane, and double rather than single aliquots of the ethanol extract were assayed. Samples and cortisol standards were dissolved in ethanol-saline prior to assay. The radioligand was $\left[{ }^{3} \mathrm{H}\right]$ cortisol, and Fuller's earth was used to absorb free cortisol. The overall sensitivity of this CPB method for plasma corticosteroids is $0.3 \mu \mathrm{g} / \mathrm{dl}$ plasma. In the range of $3.0 \mu \mathrm{g} / \mathrm{dl}$ to $10.0 \mu \mathrm{g} / \mathrm{dl}$ (typical plasma cortisol concentrations), the assay has a precision better than or equal to $\pm 8.3 \%$. The intraassay coefficient of variation is $2 \%$ and the interassay coefficient of variation is $7 \%$. The method is not completely specific for cortisol, as it also measures other glucocorticoids and gonadal steroids in plasma to a small extent. In terms of their contribution to total plasma corticosteroids measured in this assay, the most significant of these noncortisol steroids are corticosterone, cortisone, and 11-denxycortisol.

5. Data Handling. Biochemicai data (peptide and steroid individual values) and clinical data (age, sex, diagnosis, weight loss, Hamilton score, day of menstrual cycle, etc.) were all entered in a data base using dBase III, (Ashton-Tate) on an IBM-AT and interfacing with a more detailed clinical data base maintained by the Clinical Studies Unit on the main computer system at the University of Michigan (MTS). RS-1 (Bolt \& Beranck and Newman, Inc., Boston, Mass.) was used for statisticai analysis including $t$-tests, correlation coefficients, and $\chi^{2}$ tests.

\section{Results}

\section{Dexamethasone Effect in Normal Controls}

The results of the study in normal controls are included in Table 1 and Figure 1. These data validate the overlap criterion in a nonpsychiatric population. The individual predex and postdex values are displayed to demonstrate the use of the criterion. Every subject shows mean postdexamethasone values with a confidence limit (SEM) that falls below the confidence limits of the mean predexamethasone values, that is, there is no overlap between the individual predexamethasone and postdexamethasone means. (For example, for Subject 7 the postdex higher limit is $2.86+0.08=2.94$. His predex lowest limit is $3.47-0.31=3.16$. Because the lowest limit predex is higher than the highest limit postdex there is no overlap between the confidence limits of the two means, and the subject is termed a "suppressor"). Given our operational definition, we would consider all these normal controls "suppressors." In addition, the entire group exhibits significantly decreased postdex values relative to predex (paired $t$ test, $p<0.0001$ ).

\section{Replication and Extension of Previous Results}

In the previous study, (Matthiews et al 1986) termed Study I, we reported our findings on a total of 47 MDD subjects from 3 centers ( 18 University of Michigan, 16 Henry Ford Hospital, and 13 Yale University), and 16 psychiatric control patients (a combined pool from University of Michigan and from Yale University). The composition of patients in the present study (termed Study II) was summarized in the Methods section.

The results of the current study (Study II) are summarized in Table 2, Panel B, using the criterion of "overiap between SEM" for the $\beta$-END/ $\beta$-LPH. As mentioned above, each of the normal control subjects showed a clear suppression postdex using the overlap criterion. Furthermore, 6 of 8 psychiatric controls suppressed $\beta$-END/ $\beta$-LPH secretion. Indeed, the psychiatric control group predex mean was $2.54 \pm 0.5$ and the postdex mean was $0.75 \pm 0.2$, a significant treatment effect (paired $t$-test $2 p=0.008$ ). Using the overlap criterion, $57 \%$ of the MDD patients failed to suppress, as Jmpared to $25 \%$ of the psychiatric controls. The frequency of cortisol nonsuppression after dexamethasone was 33\% in the MDD group and 0\% in the control group (Interestingly, in our small sample of patients with a current diagnosis of mania we obtained a $60 \%$ rate of $\beta$-END/ $\beta$-LPH nonsuppression but $20 \%$ cortisol nonsuppression).

Table 2 also compares the results from the recent study with those of the subset of patients from our first report who were from the University of Michigan (Study I), using the overlap criterion. In general, Study II replicated Study I with remarkable closeness. The frequencies of $\beta-E N D / \beta-$ LPH nonsuppression and cortisol nonsuppression in both the MDD and the psychiatric controls were quite comparable. Over $50 \%$ of the MDD patients from either study are abnormal with the $\beta$-END/ $\beta$-LPH assay, whereas $33 \%$ are abnormal with the cortisol assay (Table 2, Panels A, B). The most prominent difference in the results from the two studies was the frequency with which cortisol and $\beta$ - 
Table 1. Individual Values for Normal Controls

\begin{tabular}{|c|c|c|c|c|c|c|}
\hline \multirow[b]{2}{*}{ Subject } & \multirow[b]{2}{*}{ Sex } & \multirow[b]{2}{*}{ Age } & \multicolumn{2}{|c|}{$\beta$-Endorphin (fmoles/ml) } & \multicolumn{2}{|c|}{ Cortisol ( $\mu \mathrm{g} / \mathrm{dl})$} \\
\hline & & & Predex & Postdex & Predex & Postdex \\
\hline 1. & $\mathbf{M}$ & 24 & $3.34 \pm 0.76$ & Not Detectable $(0.05)$ & $5.03 \pm 0.98$ & $1.18 \pm 0.02$ \\
\hline 2. & $\mathbf{M}$ & 24 & $1.98 \pm 0.18$ & Not Detectable (0.05) & $4.33 \pm 0.3$ & $1.20 \pm 0.04$ \\
\hline 3. & $\mathbf{M}$ & 27 & $1.98 \pm 0.23$ & Not Detectable (0.0ذ) & $1.83 \pm 0.17$ & $0.80 \pm 0.07$ \\
\hline 4. & $\mathbf{M}$ & 32 & $1.21 \pm 0.63$ & $0.33 \pm 0.23$ & $1.88 \pm 0.17$ & $0.98 \pm 0.1$ \\
\hline 5. & $\mathbf{M}$ & 40 & $1.79 \pm 0.82$ & $0.25 \pm 0.08$ & $3.68 \pm 0.6 i$ & $1.13 \pm 0.16$ \\
\hline 6. & $\mathbf{M}$ & 60 & & $0.27 \pm 0.03$ & $6.50 \pm 0.51$ & $1.30 \pm 0.05$ \\
\hline 7. & $\mathbf{M}$ & 68 & $3.47 \pm 0.31$ & $2.86 \pm 0.08$ & $10.68 \pm 0.33$ & $2.53 \pm 0.34$ \\
\hline 8. & $\mathbf{F}$ & 20 & $0.90 \pm 0.74$ & $0.05 \pm 0.01$ & $5.1 \pm 0.64$ & $0.93 \pm 0.04$ \\
\hline 9. & F & 26 & $1.99 \pm 0.15$ & $0.50 \pm 0.17$ & $7.1 \pm 0.55$ & $1.40 \pm 0.10$ \\
\hline 10. & $\mathrm{~F}$ & 26 & $1.34 \pm 0.33$ & $0.06 \pm 0.01$ & $2.35=0.16$ & $1.20 \pm 0.07$ \\
\hline 11. & $\mathrm{~F}$ & 27 & $0.87 \pm 0.14$ & $0.21 \pm 0.05$ & $3.53 \pm 0.38$ & $1.73 \pm 0.09$ \\
\hline 12. & F & 35 & $2.26 \pm 0.13$ & $0.36 \pm 0.19$ & $2.98 \pm 0.18$ & $0.88 \pm 0.02$ \\
\hline 13. & $\mathrm{~F}$ & 40 & $1.31 \pm 0.18$ & $0.17 \pm 0.01$ & $5.43 \pm 0.49$ & $1.43 \pm 0.09$ \\
\hline 14 & $F$ & 50 & $1.96 \pm 0.22$ & $0.66 \pm 0.6$ & $5.05 \pm 0.60$ & $2.98 \pm 0.14$ \\
\hline 15. & F & 54 & $1.93 \pm 0.05$ & $1.20 \pm 0.23$ & $4.65 \pm 0.48$ & $0.75 \pm 0.06$ \\
\hline 16. & F & 66 & $1.13 \pm 0.15$ & $0.65 \pm 0.21$ & $3.25 \pm 0.32$ & $0.33 \pm 0.25$ \\
\hline$x \pm \mathrm{SEM}$ & Male & & $2.16 \pm 0.34$ & $0.55 \pm 0.38$ & $4.85 \pm 1.16$ & $1.30 \pm 0.20$ \\
\hline & Female & & $1.52 \pm 0.17$ & $0.43 \pm 0.12$ & $4.38 \pm 0.49$ & $1.29 \pm 0.25$ \\
\hline & All & & $1.80 \pm 0.19$ & $0.48 \pm 0.18$ & $4.58 \pm 0.56$ & $1.30 \pm 0.16$ \\
\hline
\end{tabular}
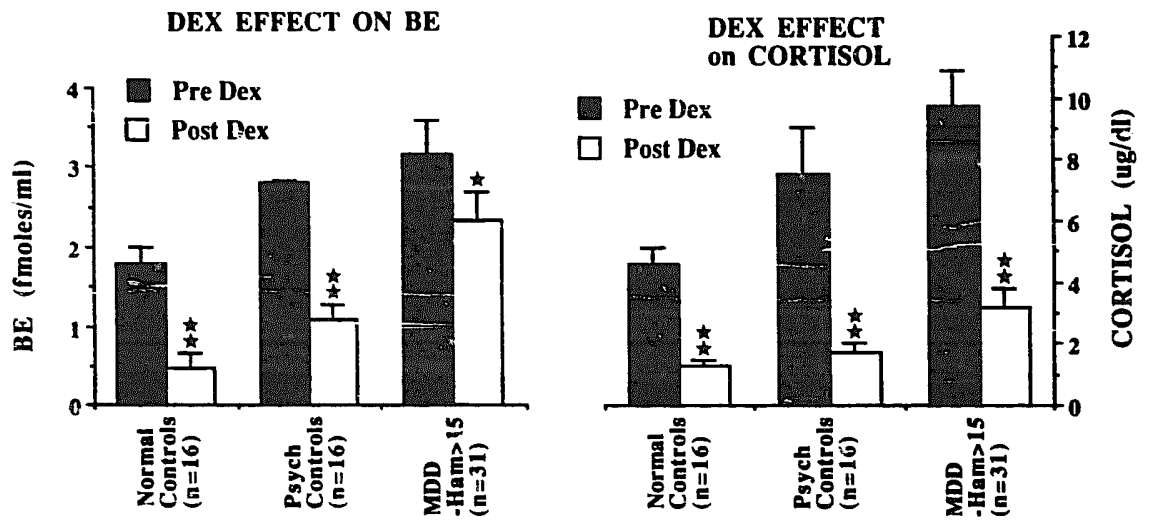

Figure 1. Endocrine profiles from combined Study I and Study II, with Pre Dex and Post Dex values for normal controls, psychiatric controls, and MDD subjects with Hamilton scores $>15$.

Table 2. Dex Effect in UMM Studies I and ii: Rate of Non-Suppression

\begin{tabular}{|c|c|c|c|c|c|c|c|c|c|c|c|c|}
\hline & \multicolumn{4}{|c|}{ A: Study I } & \multicolumn{4}{|c|}{ B: Study II } & \multicolumn{4}{|c|}{ C: Study I \& II } \\
\hline & $n$ & $\beta$-END & Cort & Either & $n$ & $\beta$-END & Cort & Either & $n$ & $\beta$-END & Cort & Either \\
\hline \multirow{2}{*}{$\begin{array}{l}\text { Normal } \\
\text { conirols }\end{array}$} & \multirow[t]{2}{*}{4} & $0 \%$ & $0 \%$ & $0 \%$ & \multirow[t]{2}{*}{16} & $0 \%$ & $0 \%$ & $0 \%$ & \multirow[t]{2}{*}{20} & $0 \%$ & $0 \%$ & $0 \%$ \\
\hline & & $0 / 4$ & $0 / 4$ & $0 / 4$ & & $0 / 16$ & $0 / 16$ & $0 / 16$ & & $0 / 20$ & $0 / 20$ & $0 / 20$ \\
\hline \multirow{2}{*}{$\begin{array}{l}\text { Psych } \\
\text { controls }\end{array}$} & \multirow[t]{2}{*}{8} & $13 \%$ & $0 \%$ & $13 \%$ & \multirow[t]{2}{*}{8} & $25 \%$ & $12 \%$ & $25 \%$ & \multirow[t]{2}{*}{16} & $18 \%$ & $6 \%$ & $18 \%$ \\
\hline & & $1 / 8$ & $0 / 8$ & $1 / 8$ & & $2 / 8$ & $1 / 8$ & $2 / 8$ & & $3 / 16$ & $1 / 16$ & $3 / 16$ \\
\hline \multirow{2}{*}{$\begin{array}{r}\text { All MDD } \\
\text { patients }\end{array}$} & \multirow[t]{2}{*}{18} & $50 \%$ & $33 \%$ & $72 \%$ & \multirow[t]{2}{*}{21} & $57 \%$ & $33 \%$ & $57 \%$ & \multirow[t]{2}{*}{39} & $54 \%$ & $33 \%$ & $64 \%$ \\
\hline & & $9 / 18$ & $6 / 18$ & $13 / 18$ & & $12 / 21$ & $7 / 21$ & $12 / 21$ & & $21 / 39$ & $13 / 39$ & $25 / 39$ \\
\hline MDD Pts & 17 & $53 \%$ & $29 \%$ & $71 \%$ & 14 & $57 \%$ & $42 \%$ & $57 \%$ & 31 & $55 \%$ & $35 \%$ & $65 \%$ \\
\hline HDRS $>15$ & & $9 / 17$ & $5 / 17$ & $12 / 17$ & & $8 / 14$ & $6 / 14$ & $8 / 14$ & & $17 / 31$ & $11 / 31$ & $20 / 31$ \\
\hline
\end{tabular}


END/ $\beta$-LPH nonsuppression occurred in the same 79tients. In Study I, a number of patients had only one abnormality, but a combination of the two measures indicated $70 \%$ of patients showed nonsuppression of either $\beta$-END/ $\beta$-LPH or cortisol after dexamethasone. In Study II, every subject who was $\beta$-END/ $\beta$-LPH abnormal was also cortisol abnormal. Thus, combining the two tests gave no increment over measuring $\beta$-END/ $\beta$-LPH alone. The reason for this discrepancy is unclear. Nevertheless, Study II confirmed the major conclusions of Study I: (1) The $\beta$ END/ $\beta$-LPH measures, as used with the overlap criterion, reveals a significant level of abnormality in the MDD patients in contrast to other psychiatric subjects, (2) the $\beta$ $\mathrm{END} / \boldsymbol{\beta}$-LPH assay demonstrates at least as a high a rate of escape from dexamethasone as the cortisol assay, and (3) there is considerable heterogeneity in the MDD population, in that a substantiai number of significantly depressed patients (HLRS $>15$ ) respond normally on one or both measures.

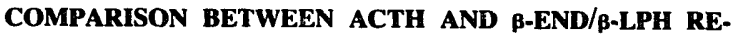
SPONSE. It could be suggested that the dissociation between cortisol and $\beta$-END/ $\beta$-LPH responses to dexamethasone observed in the first study is caused by different effects of dexamethasone on the secretion of ACTH and $\beta$-END/ $\beta-\mathrm{LPH}$, rather than differences in the responses of the pituitary and adrenal. To test this possibility, we examined the ACTH and $\beta-E N D / \beta-L P H$ responses to dexamethasone in a small subgroup of subjects. The results are summarized in Table 3. As can be seen using the "overlap criteria," there is complete concordance between the two assays-not necessarily in absolute levels, but in categorizing a subject as demonstrating normal or abnormal suppression. Examining both ACTH and $\beta$-END/ $\beta$ -
LPH responses to dexamethasone, we found that there was complete concordance between assayjs fús acin pativint. The $\beta E$ RIA was used as the primary measure of pituitary tone because of its high sensitivity relative to the ACTH RIA ( $0.25 \mathrm{fmoles} / \mathrm{ml}$ versus $2 \mathrm{fmoles} / \mathrm{ml})$. Such sensitivity is particularly critical when looking at nightly postdex values, which can be very low.

COMBINED ANALYSIS OF UNIVERSITY OF MICHIGAN SUBBJECTS FROM STUDIES I \& u). Having shown that the results from both University of Michigan studies are highly consistent, we have decided to combine them for further analyses (total MDD, $n=39$; MDD with HDRS $>15$, $n=31$; total psychiatric controls, $n=16$ ). Because of their small number, patients with a diagnosis of mania were not inciuded in this combined analysis.

The last column of Table 2 (Panel C) sumrnarizes the incidence of nonsuppression across the two studies or both $\beta$-END/ $\beta$-LPH and cortisol measures for the combined groups. As can be seen, the MDD patients exhibit a $54 \%$ rate of abnormality in $\beta-E N D / \beta-L P H$ measures, $33 \%$ on cortisoil measures, and $64 \%$ on eituter. NúbD patients with Hamilton scores greater than 15 had slightly higher rates. The psychiatric controls have a combined rate of abnormality of $18 \%$ and the normal controls $0 \%$. Because of the larger numbers resulting from the combination of samples, we can now average absolute values of peptides with less concern for possible interassay differences. Figure 1 summarizes these results focusing on the MDD patients with Hamilton scores greater than 15 . This summary compares these patients $(n=31)$ with the 16 control subjects from Study II, and 16 psychiatric controls from Studies I and II. Dexamethasone causes a significant reduction in both $\beta$-END/ $\beta$-LPH and cortisol

Table 3. Relationship between ACTH and $\beta$-End/ $\beta$-LPH Assays $(+)$ Means Escape and $(-)$ Means Suppress

\begin{tabular}{|c|c|c|c|c|c|c|}
\hline \multirow{2}{*}{$\begin{array}{l}\text { Subject } \\
\text { number }\end{array}$} & \multicolumn{2}{|c|}{$\beta$-END/ $\beta$-LPH assay } & \multicolumn{2}{|c|}{ ACTH-assay } & \multicolumn{2}{|c|}{ Cortisol assay } \\
\hline & Pre & Post & Pre & Post & Pre & Post \\
\hline \multirow[t]{3}{*}{$\# 1$} & 1.16 & 1.27 & 2.15 & 2.38 & 1.61 & 1.00 \\
\hline & +0.37 & +0.56 & +0.24 & +0.26 & +0.37 & +0.26 \\
\hline & \multicolumn{2}{|c|}{$(+)$} & \multicolumn{2}{|c|}{$(+)$} & \multicolumn{2}{|c|}{$(-)$} \\
\hline \multirow[t]{3}{*}{$\# 2$} & 2.23 & 1.91 & $2.5 i$ & 2.61 & 13.56 & 9.02 \\
\hline & $\pm J .4$ & +0.3 & +0.3 & +0.28 & +3.75 & +1.13 \\
\hline & \multicolumn{2}{|c|}{$(+)$} & \multicolumn{2}{|c|}{$(+)$} & \multicolumn{2}{|c|}{$(+)$} \\
\hline \multirow[t]{3}{*}{$\# 3$} & 2.29 & 1.56 & 2.95 & 2.1 & 6.84 & 1.42 \\
\hline & +0.18 & +0.3 & +0.06 & +0.3 & +0.96 & +0.73 \\
\hline & \multicolumn{2}{|c|}{$(-)$} & \multicolumn{2}{|c|}{$(-)$} & \multicolumn{2}{|c|}{$(-)$} \\
\hline \multirow[t]{3}{*}{$\# 4$} & 2.24 & 2.18 & 2.38 & 1.98 & 3.02 & 0.73 \\
\hline & +1.0 & +0.65 & +0.35 & +0.3 & +0.39 & +0.26 \\
\hline & \multicolumn{2}{|c|}{$(+)$} & \multicolumn{2}{|c|}{$(t)$} & \multicolumn{2}{|c|}{$(-)$} \\
\hline \multirow[t]{3}{*}{ \#5 } & 1.51 & 1.92 & 2.43 & 2.38 & 6.90 & 2.59 \\
\hline & +0.13 & +0.31 & +0.26 & +0.46 & +1.33 & +0.53 \\
\hline & \multicolumn{2}{|c|}{$(+)$} & \multicolumn{2}{|c|}{$(+)$} & \multicolumn{2}{|c|}{$(-)$} \\
\hline
\end{tabular}


levels in all three groups. However, the peptide decrease in MDD patients is less pronounced than in the controls (radio $\beta$-END/ $\beta$-LPH postdex: $\beta$-END/ $\beta$-LPH predex $=26 \%$ for normal controls, $39 \%$ for psychiatric controls, $74 \%$ for MDD subjects). Finally, these data suggest that POMC products are hypersecreted by MDD patients at rest, at least for the 4 PM time period relative to normals, but not relative to psychiatric controls (MDD: $3.16 \pm 0.42 \mathrm{fnole} / \mathrm{ml}$; Controls: $1.8 \pm 0.19 \mathrm{fmoles} / \mathrm{ml}$ Psychiatric Controls: $2.79 \pm 0.3$ ). This represents a $75 \%$ increase over normals, but only a $13 \%$ elevation relative to psychiatric controls.

\section{The Effect of Individual Variables in the Response to Dexamethasone}

In spite of the fact that approximately two-thirds of the MDD patients showed a lack of suppression of HPA function following the dexamethasone challenge, our results again showed evidence of heterogeneity among the subjects. One-third appeared to have normal suppressive responses to dexamethasone with both assays, and a number of subjects were nonsuppressive with cnly one of the two hormonal measures. To further explore the source of such heterogeneity, we examined the effects of a number of variables including weight loss, severity of the depression, age and sex on both baseline measures and postdex responses. Our results showed that the effects of weight change on the outcome were small, and that severity may contribute, but only modestly, to basal and postdexamethasone levels, as detailed in a separate report MeadorWoodruff et al 1987). Therefore, we focused on the effects of age and sex on the HPA profiles of our subjects.

EFFECT OF AGE AND SEX ON RESTING HORMONE LEV. ELS AND POST-DEX RESPONSES. There was only a minor correlation between age and resting cortisol when all subjects (MDD and control, men and women) were combined: $r=0.31$. The overall correlation of age with resting $\beta$ $\mathrm{END} / \beta$-LPH is $r=0.18$. However, when the MDD patients with HDRS $>15(n=28)$ were entered alone into a best-fit analysis, a two component function emerged (not shok ..;, demonstrating a major positive correlation beginning only around 40-45 years of age. Indeed, the correlation coefficient between age and resting cortisol from the age of 45 onward is $r=0.47(p<0.5)$ for both men and women $(n=18)$ (Figure 2). However, there was an obvious gender dirference relative to this correlation with the males not fitting well. On the other hand, the correlation coefficient becomes quite substantial when MDD females over 45 are considered alone $(n=15, r=0.69$ $p<0.01$ ). Thus, in that subgroup of female depressive over 45 , age accounted for $48 \%$ of the variance of resting cortisol measures (Figure 2).

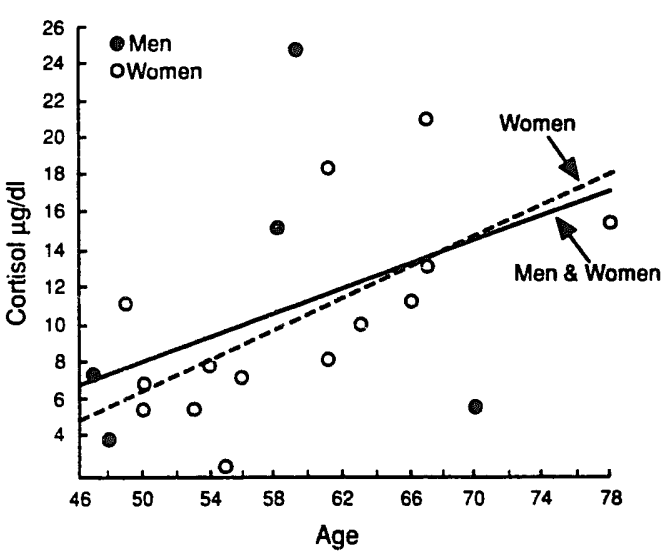

Figure 2. Age versus basal cortisol in E.D. patients over 45 years nld.

On the other hand, the MDD patients showed an inverted curvilinear two-component function when correlating resting $\beta-\mathrm{END} / \beta-\mathrm{LPH}$ with age regardless of sex (not shown). After 45 years of age, there was a significant negative correlation of resting $\beta$-END/ $\beta$-LPH with age $(r=-0.54, n=18, p<0.02)$, which was true in both men and women (Figure 3).

These results suggest that in MDD patients over 45 years of age, resting cortisol increases with age. This pattern is particularly clear in women over the age of 45 as it accounts for approximately $50 \%$ of the resting cortisol

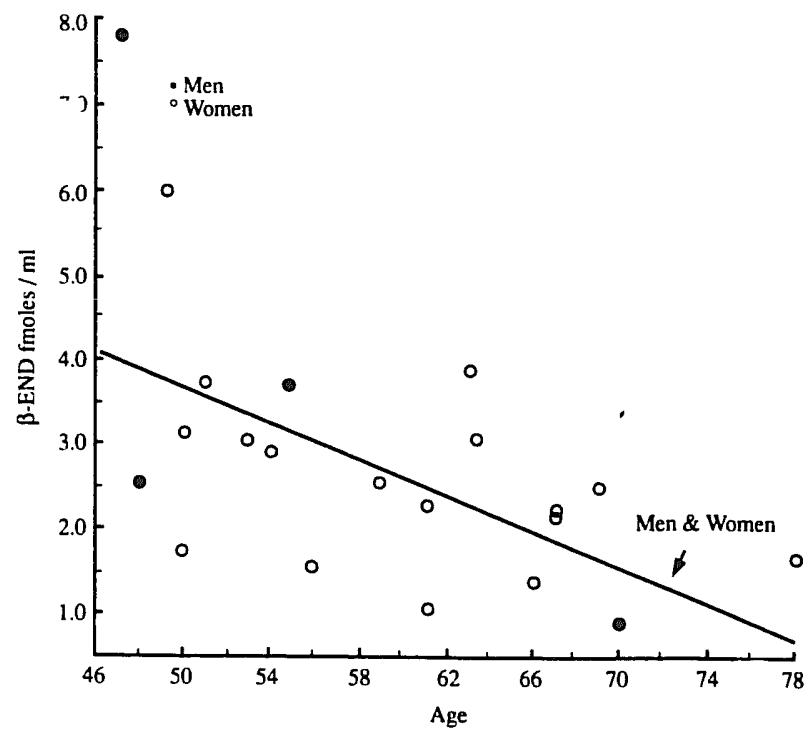

Figure 3. Age versus mean basal $\beta$-endorphin in E.D. patients over 45 years old. 
variance. On the other hand, premenopausal women appear more variable than men. Furthermore, aging is also accompanied by a decrease in $\beta$-END/ $\beta$-LPH resting levels, possibly because of the negative feedback effect of the high cortisol levels on the anterior lobe corticotrophs, with this accounting for approximately $30 \%$ of the variance.

AGE AND POSTDEX CORTISOL AND $\beta$-END/B-LPH. If age is correlatea with increased basal cortisol after age 45 , how does age affect subsequent responsiveness to dexamethasone? There appears to be a clear relationship, which can be seen in a number of ways. For instance, we compared the age of DST nonsuppressor and DST suppressor patients across three groups of MDD patients-the current University of Michigan MDD subjects (HDRS $>15, n$ $=28$ ), the Henry Ford Group (reported in Matthews et al 1986, $n=16$ ), and a separate group of subjects in the University of Michigan data base studied by Carroll and collaborators for whom cortisol was measured both predexamethasone and postdexamethasone $(n=26)$. Across these $70 \mathrm{MDD}$ subjects, there were 31 nonsuppressors, and 39 suppressors; the mean age for DST cortisol nonsuppressor patients was 12 years higher than the mean age for DST suppressors ( 58.4 versus 46.4 , with an overall mean of 52).

Figure 4 and Table 4 show a different way of analyzing the interaction between resting hormone levels, age, and the likelihood of being nonsuppressive with dexamethasone. Figure 4 depicts resting steroid and peptide levels for the University of Michigan group; the domain outlined by the dashed rectangle delineates the "normal domain" of resting values, that is, range of prejexamethasone values found in $95 \%$ of the control subjects. Thus, over $95 \%$ of our controls had 4 PM basal cortisol values below 13 $\mathrm{\mu g} / \mathrm{dl}$ and basal $\beta$-END/ $\beta$-LPH values below $4.5 \mathrm{fmoles} / \mathrm{ml}$.

As can be seen from Figure 4, a number of the MDD patients were outside this normal domain. In particular, six subjects had unusually high cortisol levels (i.e. $>13$ $\mu \mathrm{g} / \mathrm{dl})$. These subjects were $100 \%$ positive on the DST with the cortisol assay, and $66 \%$ positive on the $\beta-E N D / \beta-$ LPH assay. Interestingly, their mean age is $65.0 \pm 3.0$. On the other hand, the group that had a nornal corisol predex, had only a $5 \%$ rate of incidence of DST abnormality with the cortisol assay and a mean age of 45.4 (Table 4). Thus, if a subject has high basal cortisol, the chances are good that he/she also is both older and a DST nonsuppressor.

That this observation may have some general validity can be seen from the second part of Table 4, showing the same analysis for the previously described Henry Ford Hospital group. Here again, subjects with high resting cortisol $(>13 \mu \mathrm{g} / \mathrm{dl})$ have a $100 \%$ chance of being a DST nonsuppressor on both cortisol and $\beta-E N D / \beta-L P H$ assays, and are older than subjects with lower resting cortisol (61.8 \pm 4.1 versus $50.4 \pm 4.5)$.

Thus, there is a complex interaction between age, resting cortisol level, and DST nonsuppression. The effect of age on $\beta$-END/ $\beta$-LPH abnormality is not quite as evident. We only have two subjects with high $\beta-E N D / \beta-L P H$ levels

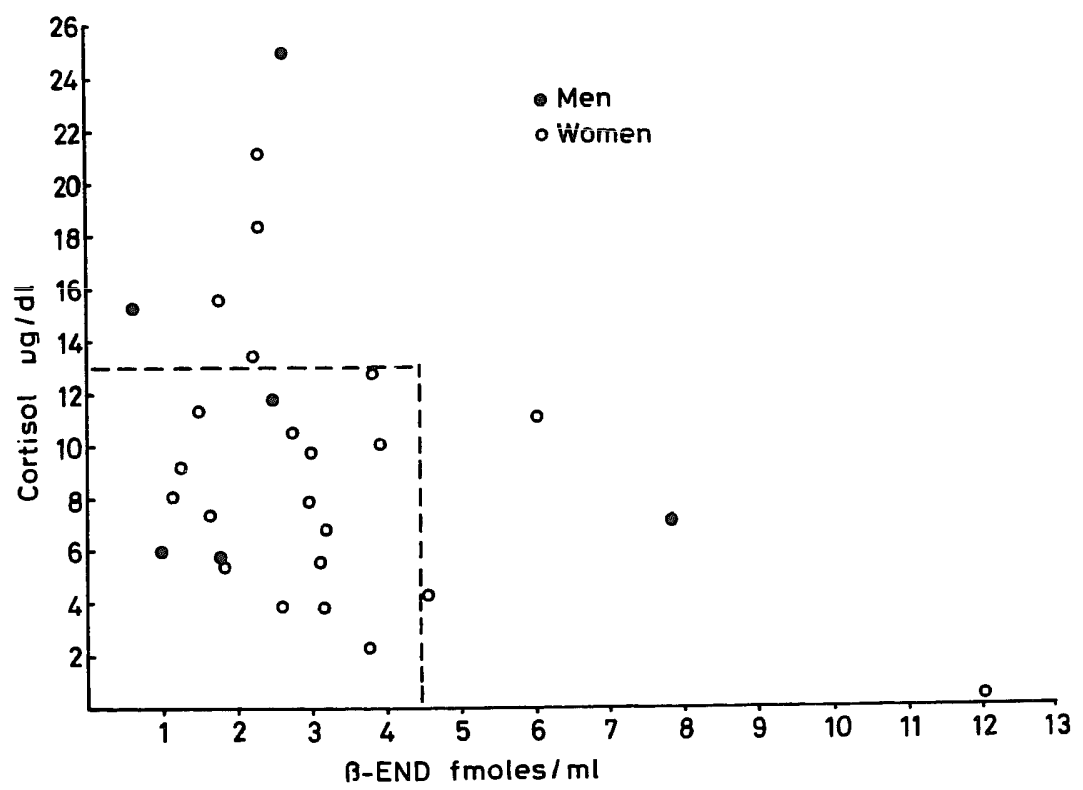

Figure 4. Mean basal $\beta$-endorphin versus mean basal cortisol in E.D. patients. 
Table 4. Cortisol Resting Levels versus Age in MDD (Studies 1 \& 2)

\begin{tabular}{|c|c|}
\hline \multicolumn{2}{|c|}{ University of Michigan Subjects } \\
\hline $\begin{array}{c}\text { Normal resting level: }<13 \text { at } 4 \\
\text { PM }\end{array}$ & $\begin{array}{l}\text { Hi Resting Levels: } \\
>13 \text { at } 4 \mathrm{PM}\end{array}$ \\
\hline $\begin{array}{l}n=22 \\
X \text { Age: } 45.36 \pm 3.3 \\
\bar{X} \text { predex cuit }=7.73 \pm 0.62 \\
\bar{X} \text { postdex cort }=1.57 \pm 0.27 \\
c_{0} \text { Cort positive }=1 / 22=5 \% \\
\% \beta E \text { "nonsuppressor" }=12 / 22 \\
\quad=54 \%\end{array}$ & $\begin{array}{l}n=6 \\
X \text { Age: } 65 \pm 3.0^{4} \\
\bar{X} \text { predex cort }=18.2 \pm 1.74 \\
\bar{X} \text { postdex cort }=9.6 \pm 0.06 \\
\% \text { Cort positive }=6 / 6=100 \% \\
\% \beta E \text { "nonsuppressor" }=4 / 5 \\
\quad=66 \%\end{array}$ \\
\hline \multicolumn{2}{|c|}{ Henry Ford Subjects } \\
\hline $\begin{array}{l}\text { Normal resting levels: } \\
\quad<13 \text { at } 4 \mathrm{PM}\end{array}$ & Hi resting levels: $>13$ at $4 \mathrm{PM}$ \\
\hline $\begin{array}{l}n=9 \\
X \text { Age }=50.4 \pm 4.5 \\
\bar{X} \text { predex cort }=8.36 \pm 1.13 \\
\bar{X} \text { postdex cort }=4.29 \pm 1.09 \\
\% \text { Cort positive }=4 / 9=44 \% \\
\% \beta E \text { "nonsuppressor" }=5 / 9 \\
\quad=56 \%\end{array}$ & $\begin{array}{l}n=5 \\
X \text { Age }=61.8 \pm 4.1^{\circ} \\
\bar{X} \text { predex cort }=16.38 \pm 2.1 \\
\bar{X} \text { postdex cort }=16.68 \pm 3.55 \\
\% \text { Cort positive }=5 / 5=100 \% \\
\% \beta E \text { "nonsuppressor" }=5 / 5 \\
\quad=100 \%\end{array}$ \\
\hline
\end{tabular}

aSignificantly different from "normal resting levels" group- $-p<0.02$.

at rest. Because of negative-feedback mechanisms, high cortisol often leads to normal or low $\beta$-END/ $\beta$-LPH levels, which renders the analysis of that variable more difficult (note in Figure 4 the absence of any subjects high on both $\beta$-END/ $\beta$-LPH and cortisol).

\section{Discussion}

The present study permits a number of conclusions, which extend our previous findings reported by Matthews et al (1986). Firstly, the data confirm our results which showed that MDD patients have only mildly elevated basal levels of $\beta$-END/ $\beta$-LPH at 4 PM compared to psychiatric controls, although they exhibit a $75 \%$ elevation over normal controls. Yet, as a group, the MDD subjects show decreased suppression to dexamethasone in comparison to either control group. Secondly, our findings support the usefulness of employing an individual rather than group criterion for abnormal peptide responsiveness to dexamethasone (e.g., the "overlap of the SEM" criterion). This criterion is further validated by the use of a normal (nonpsychiatric) control group including both men and women with an age range of 20 to 68 , ali of whom suppressed by the overlap criterion. Thirdly, the $\beta-E N D / \beta-L P H$ assay continues to detect, as nonsuppressors, a number of subjects not detected by the cortisol assay. In addition, as shown in a small group of patients, this does not appear to be caused by a dissociation between ACTH and $\beta$ END/ $\beta$-LPH responsiveness, as these two peptides appear to change in synchrony. Rather, the dissociation appears to be caused by the different regulatory mechanisms at the level of the pituitary corticotroph versus the adrenal cortex. Fourthly, the combination of the two assays, following dexamethasone, that is, $\beta$-END/ $\beta$-LPH and cortisol, shows about two-thirds of MD patients to be nonsuppressors, whereas psychiatric controls exhibit an $18 \%$ rate of nonsuppression on the cominined measures, and normal controls have a $0 \%$ rate of nonsuppression. The low rate of nonsuppression in our normal control subjects relative to the 5\%-10\% reported in the literature (Arana et al 1985) may be due to our use of catheters followed by a rest period, which insures minimal stress at the time of blood collection.

In addition, the present study examines some of the possible sources of variance between subjects in terms of neuroendocrine profile. Given that they all carry the same diagnosis, MDD, and are "in episode," why are some abnormal on one HPA axis measure, some on both measures, and some on neither? A major factor appears to be the interaction of hormonal basal and postdexamethasone levels with both age and sex. The age plays an important role in determining basal and postdexamethasone cortisol levels has been previously documented (Halbreich et al 1984; Oxenkrug et al 1983; Lewis et al 1984; Alexopoulos et al 1984). In particular, basal cortisol levels are highly positively correlated with age in older (over 45 ) females, accounting for $48 \%$ of the variance in this particular sample. $\beta$-END/ $\beta$-LPH levels are negatively correlated with age, suggesting generally intact negative feedback of the resting cortisol levels upon $\boldsymbol{\beta}$-END/ $\boldsymbol{\beta}$-LPH secretion. If an older female has abnormally high cortisol, she has an extremely good chance of being found DST nonsuppressive on the cortisol assay, that is, failing to suppres $s$ below the $5 \mu \mathrm{g} / \mathrm{dl}$ cut-off. This does not, however, indicate a system completely insensitive to negative feedback, as such a patient often will decrease cortisol secretion postdexamethasone, but not to normal levels. These older patients may truly have developed adrenal hyperplasia. In addition, they may have slightly altered set points to negative steroid feedback either at the limbic or pituitary level, resulting from chronically elevated steroid levels. It should be noted here that aging in nondepressed females does not lead to significant changes in resting cortisol levels at any time of the day (Tinngco et al 1986). It also should be noted that aged depressives tend to have higher severity ratings and have had more episodes of depression. Thus, this relationship between age, sex, and basal cortisol may be 
due to the interaction of these factors with some aspect of the depressive illness (chronic stress, predisposing factors, drug history, etc.). Although our own sample is relatively small, a recent report by Maes et al (1990) supports these conclusions. Their data suggested that $54 \%$ of the variance in postdex cortisol could be explained by baseline cortisol secretion as assessed by urinary free cortisol, age, and dexamethasone plasma leveis, independent of depressed mood.

Although the prototypical depressed, aged female with high basal cortisol is easily detected by the classical DST and to some extent by the $\beta E$ assay, the other patients are more difficult to characterize, particularly those who are normal on postdexamethasone cortisol but abnormal on $\beta$-END/ $\beta$-LPH. A subject with resting cortisol close to the $5 \mu \mathrm{g} / \mathrm{dl}$ cut-off can suppress very little and still be termed a suppressor if he goes below the cut-off. On the other hand, the $\beta-E N D / \beta-L P H$ response, as structured with the overlap method, may detect an abnormality in such a subject. Thus, part of the discrepancy between the two tests may derive from the different criteria for an "abnormal" response. Recent studies suggest that lower plasma dexamethasone levels in DST nonsuppressor patients may be responsible for some of the DST cortisol nonsuppression (Morris et al 1986; Maguire et al 1987; Wiedeman and Holsboer 1977; Johnson et al 1984; Meikle 1982). In this current study we do not have plasma dexamethasone levels. However, it is probable that a number of these depressed elderly patients with hypercortisolinemia may have low plasma dex levels that account for the cortisol nonsuppression. Whether lower plasma dex leveis are responsible for the $\beta-E N D / \beta-L P H$ in these patients is not clear. Data from a different group of depressed patients studied by our group (Young et al 1992) does not demonstrate a difference in plasma dexamethasone levels between $\beta$-END/ $\beta$-LPH suppressors and nonsuppressors.

At a more conceptual level, we need to consider the issue of an abnormal $\beta$-END/ $\beta$-LPH response to dexamethasone in the face of a cortisol response that falls within a typically normal domain. How can one not respond to dexamethasone at the pituitary and suprapituitary level and yet continue to exhibit an apparently normal adrenal suppression? One possibility is that temporal considerations and differences in half-life of the hormones might be confounding results. Specifically, $\beta-E N D / \beta-L P H$ values may show escape from dexamethasone suppression first, followed by a cortisol escape. Because we assess the full endocrine profile only at one time (3:30-4:30 PM) we may be missing the later stages of such a temporal patterning. We have conducted a separate study to examine this possibility, testing our subjects at different times of the day. Our results (Young et al 1992) have shown that 4 PM is in fact, the best time to detect escape from dexamethasone for both the peptide and the glucocorticoids. Thus, time of day does not appear to explain the dissociation between cortisol and $\beta-E N D / \beta-L P H$ results. An alternative and more intriguing explanation is that there may be previously ignored negative feedback mechanisms at the level of the adrenal itself (Black et al 1961). In other words, dexamethasone could cause adrenal inhibition of steroidogenesis beyond its effects on the pituitary and limbic system (Carsia et al 1982). It is conceivable that in some subjects, dexamethasone suppression at the pituitary and suprapituitary levels becomes less effective, whereas effects at the adrenai levels are maintained.

Finally, we need to consider subjects with depression but with normal resting values of $\beta-E N D / \beta-L P H$ and cortisol, and a normal response oi both hormones to dexamethasone. In other words, these subjects appear to have a normal HPA axis both at rest and following steroid challenge. They constitute approximately $35 \%$ of our population (14 out of 39). Interestingly, men are overrepresented in this group (50\% of the men and $28 \%$ of the women are in this group). The mean age of this group $(48.4 \pm 4.9)$ is not significantly different from the general mean, and the group Hamilton score $(17.0 \pm 2.3)$ is only slightly lower than the overall Hamilton (19.46 \pm 1.9$)$. However, severity may play a role in whether a subjest has a completely normal endocrine profile. A patient with a Hamilton score greater than 25 has only a $27 \%$ chance of teing normal on the combined criteria, compared to $35 \%$ for those with HRSD scores of 15 to 24 , and $56 \%$ for those with HRSD scores below 15 .

It is therefore apparent that within the spectrum of endogenous depression, multiple endocrine profiles do emerge, which interact with the subjects' age, sex, and current severity of depression. An important issue for further consideration is whether the number of previous episodes contributes to the endocrine profile. In general, one can conceive of these unusual patterns as reflective of multiple reguiatory strategies of the HPA axis in response to unusual neuronal, hormonal, or environmental demands on that system. Given the flexibility of the HPA system and the multiplicity of its checks and balances, it is perhaps not unexpected that multiple patterns of responses appear to emerge across patients.

This work ?yas sueported in part by NIMH grant \#MH42251 (S.J. Watson and H. Akil); NIMH RSDA \#MH00427 (E. Young); NIMH grant \#MH040216 (J. Greden); The Clinical Research Center of the University of Michigan (NIMH \#RR00042); and the Department of Psychiatry. 


\section{References}

Alexopoulos GS, Young RC, Kocsis JH, Brockner N, Butler TA. Stokes PE (1984): Dexamethasone suppression test in geriatric depression. Biol Psychiatry 19:1567-1571.

Amsterdam JD, Winokur A, Caroff SN, Conn J (1982): The dexamethasone suppression test in outpatients with primary affective disorder and healthy control subjects. Am J Psychiatry 139:287-291.

Amsterdam JC, Winokur A, Abelman E, Lucki I, Richels K (1983): Co-syntropin (ACTHa ${ }^{1-24}$ ) stimulation test in depressed patients and healthy subjects. Am J Psychiatry 140:907909.

Arana GW, Baldessarini RJ, and Ornsteen M (1985): The dexamethasone suppression test for diagnosis and prognosis in psychiatry. Arch Gen Psychiatry 42:1193-1204.

Berger M, Pirke KM. Krieg CJ, et al (1985): ACTH and cortisol levels in healthy probands and psychiatric patients following the dexamethasone suppression test. Am J Psychiatry 142:268269.

Elack WC, Crampton RS, Verdesca AS, Nedelikovic RI, Hilton JG (1961): Inhibitory effect of hy trocortisone and analogues on adrenocortical secretion in dogs. Am J Physiol 201:10571060.

Brown WA, Shuey I (1980): Response to dexamethasone and subtype of depression. Arch Gen Psychiatry 37:747-751.

Cahill CA, Matthews JD, Akil H (1983): Human plasma betaendorphin-like peptides: A rapid high recovery extraction technique and validation of radioimmunoassay. J Clin Endocrinol Metab 56:992-997.

Carroll BJ (1985): Dexamethasone suppression test, in Hall RCW, Beresford TP (eds): Handbook of Psychiatric Diagnostic Procedures. New York: Spectrum.

Carroll BJ, Curtis GC, Mendels J (1967a): Neuroendocrine regulation in depression: I. Limbic system-adrenocortical dysfunction. Arch Gen Psychiatry 33:1039-1044.

Carroll BJ, Curtis GC, Mendels J (1976b): Neuroendocrine regulation in depression: II. Discrimination of depressed from nondepressed patients. Arch Gen Psychiatry 33:1051-1058.

Carroll BJ, Feinberg M, Greden JF (1980): Diagnosis of endogenous depression: Comparison of clinical research and neuroendocrine criteria. J Affective Disord 2:177-194.

Carroll B, Feinberg M, Greden JF et al (1981): A specific laboratory test for the diagnosis of melancholia: Standardization, validation, and clinical utility. Arch Gen Psychiatry 38:1522.

Carsia RV, Scanes CS, Malamed S (1984): Self rippression of corticosteroidogenesis: evidence for a role of adrenal 5a-reductase. Endocrinology 115:2464-2472.

Coppen A, Abou-Saleh M, Milln P, Metcalfe M, Harwood J, Bailey J (1983): Dexamethasone suppression test in depression and other psychiatric illness. Br J Psychiairy 142:498504.

Eipper BA, Mains RE (1980): Structure and function of proadrenocorticotropin/endorphin and related peptides. Endocr $\operatorname{Rev~1:247-262.~}$

Fang VS, Tricou BJ, Robertson A, Meltzer HY (198i): Piasma ACTH and cortisol ievels in depressed patients: Relation to dexamethasone suppression test. Life Sci 29:931-938.
Gold PW, Loriaux DL, Roy A, et al (1986). Response to corticotropin-releasing hormone in the hypercortisolism of depression and Cushing's disease. N Engl J Med 314:132935.

Guillemin R, Vargo T, Rossier J, et al (1977): Beta-endorphin and adrenocorticotropin are secreted concommitantly by the pituitary gland. Science 282:783-785.

Halbreich U, Asnis GM, Zumoff B, Nathan RS (1984): The effect of age and sex on cortisol secretion depressives and normals. Psychiatry Res 13:221-229.

Halbreich U, Asnis GM, Schindledecker R, Zurnoff B, Nathan RS (1985): Cortisol secretion in endogenous depression I. Basal plasma levels. Arch Gen Psychiarry 42:909-914.

Holsboer F, Doerr HG, Gerken A, Muller OA, Sippell WG (1983): Cortisol, 11-deoxycortisol, and ACTH concentrations after dexamethasone in depressed patients and healthy volunteers. Psychictry Res 11:15-23.

Holsboer F, Bardeleden U, Gerken A, Stalla G, Muller O (1984): Blunted corticotropin and normal cortisol response to human corticotropin-releasing factor in depression. $N$ Engl $J$ Med 311:1127.

Johnson GF, Hunt G, Kerr K, Caterson I (1984): Dexamethasone suppression test (DST) and plasma dexamethasone levels in depressed patients. Psychiatry Res 13:305-313.

Kalin NH, Weiler SJ, Shelton SE (i982): Piasma ACTH and cortisol concentrations before and after dexamethasone. Psychiatry Res 7:87-92.

Lewis DA, Pfohl B, Schlecte J, Coryell W (1984): Influence of age on the cortisol response to dexamethasone. Psychiatry Res 13:213-220.

Maes M, Jacobs M-P, Suy E, Minner B, Raus J (1990): Prediction of DST results in depressives by means of urinary free cortisol excretion, dexamethasone levels and age. Biol Psychiatry 28:349-357.

Maguire KP, Schweitzer I, Biddle N, Bridge S, Tiller JWG (1987): The dexamethasone suppression test: Importance of dexamethasone concentrations. Biol Psychiatry 22:957-967.

Matthews J, Akil H, Greden J, et al (1986): b-Endorphin/bLipotropin immunoreactivity in endogenous depression. Arch Gen Psychiatry 43:374-381.

Meador-Woodruff JH, Haskett RF, Grunhaus L, Akil H, Watson SJ, Greden JF (1987): Post-dexanilethiasone plasina cortisol and b-endorphin levels in depression: relationship to severity of illness. Biol Psychiatry 22:1137-115.

Meikle AW (1982): Dexamethasone suppression tests: Usefulness of simultaneous measurements of plasma cortisol and dexamethasone. Clin Endocrinol 16:401-408.

Morris H, Carr V, Gilliland J, Hooper M (1986): Dexamethasone concentrations and the dexamethasone suppression test in psychiatric disorders. Br J Psychiatry 148:66-69.

Nasr SJ, Rodgers C, Pandey G, Altman EG, Gaviria FM, Davis JM (1983): ACTH and the dexamethasone suppression test in depression. Biol Psychiatry 18:1069-1073.

Oxenkrug GF, Pomara N, McIntyre IM, Branconnier RJ, Stanley $M$, Gershon S (1983): Aging and cortisol resistance to suppression by dexamethasone: a positive correlation. Psychiatry Res. 10:125-130. 
Pegg PJ, Keane PM (1969): The simultaneous estimation of plasma cortisol and transcortin binding characteristics by a competitive protein binding technique. Steroids 14:705-715.

de la Pena A. Goldzieher JW (1977): Practical determination of total plasma cortisol by use of competitive protein binding. In Cooper GR, King JS (eds), Selected Methods of Clinical Chemistry. Washington, DC: American Association for Clinical Chemistry.

Pfohl B, Sherman B, Schlechte J, Stone R (1985): Pituitaryadrenal axis rhythm disturbances in psychiatric depression. Arch Gen Psychiatry 42:897-903.

Reus VI, Joseph MS, Dallman MF (1982): ACTH levels after the dexamethasone suppression test in depression. New Engl J Med 306:238-239.

Reus VI, Jospeh MS, Dallman MF (1983): Regulation of ACTH and cortisol in depression. Peptides 4:785-788.

Risch SC (1982): Beta-Endorphin hypersecretion in depression: Possible cholinergic mechanisms. Biol Psychiatry 17:10711079.

Rubin RT. Poland RE, Lesser IM, Winston RA, Blodgett N (1987): Neuroendocrine aspects of primary endogenous depression I. Cortisol secretory dynamics in patients and matched controls Arch Gen Psychiatry 44:328-336.

Sachar EJ (1967): Corticosteroids in depressive illness. Arch Gen Psychiatry 1 ::544-553.

Sachar EJ. Hellman L, Fukushima DK, Gallagher TF (1970): Cortisol production in depressive illness. Arch Gen Psychiatry 23:289-298.

Sachar EJ, Hellman L, Roffwarg HP (1973): Disrupted 24 hour pattern of cortisol secretion in psychotic depression. Arch Gen Psychiatry 28:19-24.

Schlesser MA, Winokur G, Sherman BM (1979): Genetic sub- types of unipolar primary depressive illness distinguished by hypothalamic-pituitary-adrenal axis activity. Lancet 1:739741 .

Stokes PE, Stoll PM, Koslow SH, et al (1984): Pretreatment DST and hypothalamic-pituitary-adrenocortical function in depressed patients and comparison groups: A multicenter study. Arch Gen Psychiatry 41:257-267.

Tiongco DD, Hariharan M, Haskett RF, Greden JF (1986): Age effects on HPA regulation and dexamethasone plasma levels in normal subjects. Abstract presented at the Society of Biological Psychiatry Annual Meeting, May.

Watson SJ (1982): Immunocytochemistry of peptides. Strategies for studying the role of peptides in neuronal function. Society for Neuroscience Short Course 83-92.

Wiedemann K, Holsboer F (1987): Plasma kinetics during the DST after oral and intravenous administration of the test drug. Biol Psychiatry 22:1340-1348.

Yerevanian BI, Woolf PD (1983): Plasma ACTH levels in primary depression: Relationship to the 24-hour dexamethasone suppression test. Psychiatry Res 9:45-51.

Yerevanian BI, Woolf PD, Iker HP (1983): Plasma ACTH levels in depression before and after recovery: Reiationship to the dexamethasone suppression test. Psychiatry Res 10:175-181.

Young EA, Akil H (1985): Corticotropin-releasing factor stimulation of adrenocorticotropin and beta-endorphin release: Effects of acute and chronic stress. Endocrinology 117:23-30.

Young EA, Watson SJ, Kotun J, et al (1990): $\beta$-lipotropin- $\beta$ endorphin response to low dose ovine corticotropin releasing factor in endogenous depression. Arch Gen Psychiatry 47:44957.

Young EA, Kotun J. Haskett RF, et al (1992): Association between pituitary and adrenal suppression to dexamethasone in depression. Arch Gen Psychiatry (in press). 